\title{
THE
}

\section{Comment on "Current system east of the Ryukyu Islands" by A. Nagano et al.}

\author{
Xiao-Hua Zhu \\ Jae-Hun Park \\ University of Rhode Island \\ Mark Wimbush \\ University of Rhode Island, mwimbush@uri.edu \\ Cheng-Hao Yang
}

Follow this and additional works at: https://digitalcommons.uri.edu/gsofacpubs

Terms of Use

All rights reserved under copyright.

\section{Citation/Publisher Attribution}

Zhu, X.-H., Park, J.-H., Wimbush, M., and Yang, C.-H. ( 2008), Comment on "Current system east of the Ryukyu Islands" by A. Nagano et al. J. Geophys. Res., 113, C03020, doi:10.1029/2007JC004458.

Available at: https://doi.org/10.1029/2007JC004458

This Response or Comment is brought to you for free and open access by the Graduate School of Oceanography at DigitalCommons@URI. It has been accepted for inclusion in Graduate School of Oceanography Faculty Publications by an authorized administrator of DigitalCommons@URI. For more information, please contact digitalcommons-group@uri.edu. 


\title{
Comment on "Current system east of the Ryukyu Islands" by A. Nagano et al.
}

\author{
Xiao-Hua Zhu, ${ }^{1}$ Jae-Hun Park, ${ }^{2}$ Mark Wimbush, ${ }^{2}$ and Cheng-Hao Yang ${ }^{1}$ \\ Received 9 July 2007; revised 3 September 2007; accepted 9 November 2007; published 19 March 2008.
}

Citation: Zhu, X.-H., J.-H. Park, M. Wimbush, and C.-H. Yang (2008), Comment on "Current system east of the Ryukyu Islands" by A. Nagano et al., J. Geophys. Res., 113, C03020, doi:10.1029/2007JC004458.

\section{Introduction}

[1] In a recent paper, Nagano et al. [2007] (hereafter N2007) discussed the variation of current structure and volume transport of the Ryukyu Current System (RCS) east of the Ryukyu Islands using an inverse technique with hydrographic-section data collected from three cruises. Their paper appears to be important for understanding this western boundary current, since it is based on repeated hydrographic surveys in the region east of the Ryukyu Islands. But acquiring meaningful results from inverse calculations requires great care. Fiadeiro and Veronis [1982, p. 160] say "Because inverse analysis always supplies a solution, it appeared that the assumed reference level matters less in inverse theory than in the hydrographer's [level-of-no-motion] approach. Actual computations have shown that is not true. A bad assumption leads to bad results. The 'advantage' of inverse theory is that one sees how bad the results are." The inverse technique minimizes the velocity at the reference level, and that point is indeed raised in the final paragraph of N2007, which used the reference level of $100 \mathrm{dbar}$. To determine whether this shallow reference level is an appropriate condition or not, one should investigate the effect of choosing other reference levels, in particular deeper levels. In this note, we perform two inverse calculations to calculate the current east of the Ryukyu Islands from the same data as one of the N2007 cruises but using a reference level of 2000 dbar. The resulting RCS circulation field is, we believe, more realistic than that of N2007.

[2] Three hydrographic surveys were carried out during May-June, September and October 2002 along three lines (AE, E, OS) east of the Ryukyu Islands (Figure 1). MayJune and September cruises used XCTD/XBT casts along the E line, but the October cruise collected CTD casts along all three lines. Surprisingly, absolute geostrophic velocity sections, determined by N2007 with a 100-dbar reference level, revealed large values up to $30-40 \mathrm{~cm} \mathrm{~s}^{-1}$ at 1000 dbar, the deepest level shown (Figures 2, 3b and $4 \mathrm{c}$ in

\footnotetext{
${ }^{1}$ State Key Laboratory of Satellite Ocean Environment Dynamics, Second Institute of Oceanography, State Oceanic Administration, Hangzhou, China.

${ }^{2}$ Graduate School of Oceanography, University of Rhode Island, Narragansett, Rhode Island, USA.

Copyright 2008 by the American Geophysical Union. 0148-0227/08/2007JC004458
}

N2007). We have calculated full-depth absolute geostrophic velocity sections using the inverse results of N2007 and plotted them to 3000 dbar (Figures 2a, 2b, 3a, 3b, 4a and $4 b)$. Figures $2 b, 3 b$ and $4 b$ show strong deep currents with maximum speeds of $20-50 \mathrm{~cm} \mathrm{~s}^{-1}$ on each line. In each case, note the contour lines of velocity are nearly vertical and strong currents extend to the bottom. For example, a current velocity of $-57 \mathrm{~cm} \mathrm{~s}^{-1}$ touches the bottom near 3100 dbar in the AE section. Is the computed strong deepcurrent field real, or is it an artifact of the shallow reference level? We address this question by carrying out the inverse calculation using a reference level of $2000 \mathrm{dbar}$ instead of $100 \mathrm{dbar}$, and compare results using the two reference levels. We present results for the October cruise data only, because the XBT/XCTD casts reached only $\sim 1000 \mathrm{dbar}$; also the CTD measurements provide more accuracy in the inverse calculations.

\section{Inverse Methods}

[3] We use two inverse methods to calculate the absolute geostrophic velocity: one is a typical inverse method using tapered least squares [e.g., Wunsch, 1978; Kaneko et al., 2001; Zhu et al., 2005] (hereafter Method 1) and the other is a modified inverse method (hereafter Method 2) developed by Yuan et al. [1992].

[4] To determine the optimum reference level, we first examine the initial state of the volume residuals for the computational box as a function of the reference levels (Figure 5). The norm residual volume transport (NRT) reaches a maximum value $(45.0 \mathrm{~Sv})$ at $100 \mathrm{dbar}$. At increasing depths it decreases monotonically to about 2000 dbar and thereafter it becomes almost constant (2.1 Sv). For each station pair, we have chosen our reference level to be the lesser of $2000 \mathrm{dbar}$ and the deepest common level. Note that 100 dbar (chosen by N2007) has the highest NRT, and therefore appears to be a worst-choice level (Figure 5).

[5] As in N2007, the inverse techniques are applied to the computational box bounded by the three hydrographic lines plus the Ryukyu-Island-bearing Nansei-Shoto Ridge (through which flow is assumed negligible), and the water column is divided into five potential-density layers. The water masses are assumed to be conserved in these five layers and the salt masses are assumed to be conserved in all layers except the top one. The equation system, including 


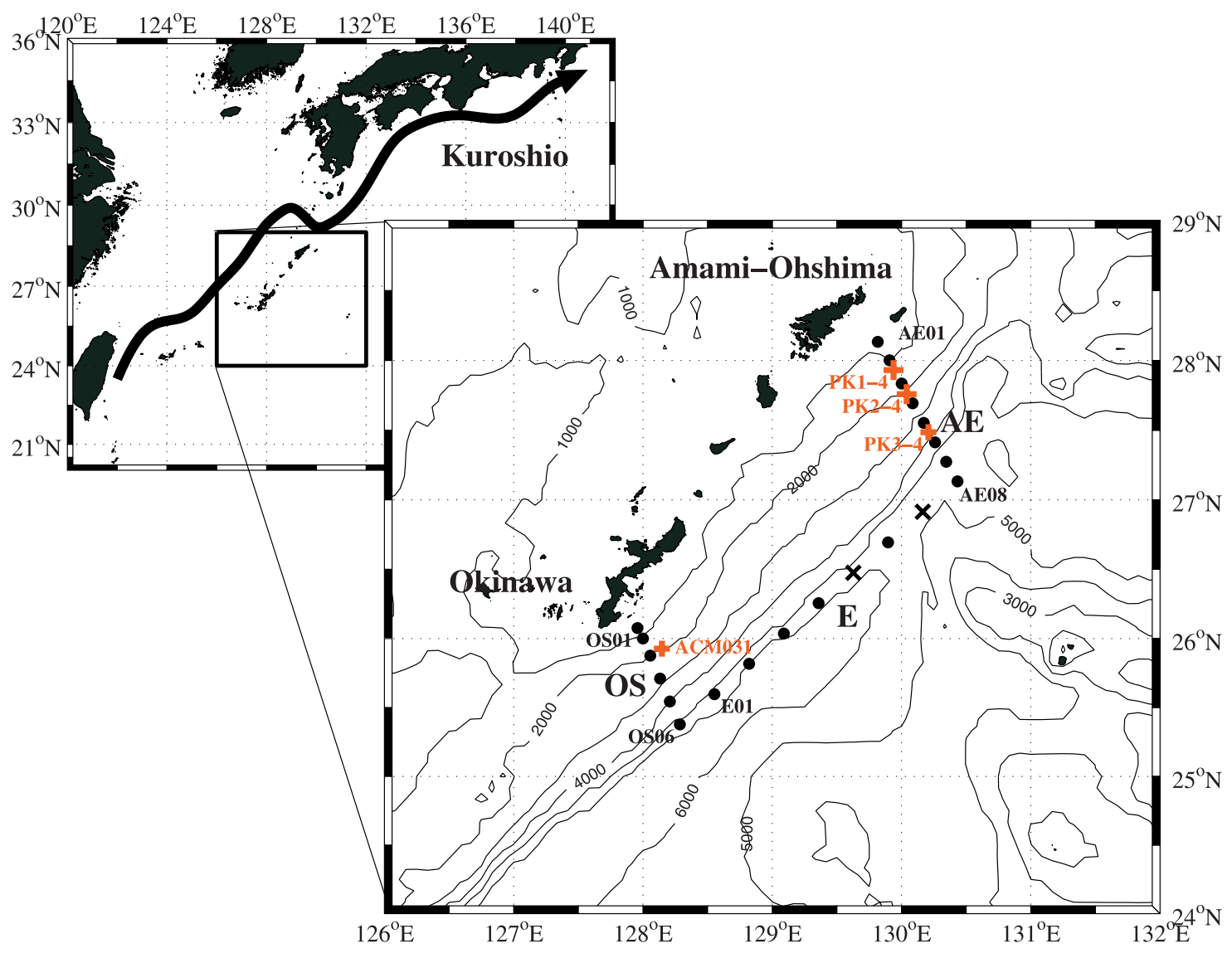

Figure 1. Location map of hydrographic stations. Solid circles and crosses indicate CTD and XCTD/ XBT stations, respectively. Red pluses indicate the current meter mooring positions. OS, E, and AE are the names of hydrographic lines. Bathymetric contours are in meters.

the mass and salt conservation equations can be written in the form

$$
\mathbf{A} \times \mathbf{b}=-\Gamma,
$$

where $\mathbf{A}$ is a $9 \times 18$ matrix, b an unknown 18-element vector of reference velocities at 18 station pairs, and $\Gamma$ a 9element vector of the initial imbalances of mass and salt with a reference level at $2000 \mathrm{dbar}$ or the deepest common level. We obtain the inverse solution to this underdetermined system by Method 1 with a tapering parameter $\sigma^{2}=$ 0.012 to keep mass imbalances below $0.3 \mathrm{~Sv}$. Solution reference velocities are $1.9 \mathrm{~cm} \mathrm{~s}^{-1}$ on average for the deep station pairs, and about $20-25 \mathrm{~cm} \mathrm{~s}^{-1}$ for the shallow station pairs (about 600 dbar, near Okinawa and AmamiOhshima Islands). For more details on Method 1 see Zhu et al. $[2005,2006]$.

[6] The equation system for Method 2 is same as equation (1), but $\mathbf{A}$ is a $9 \times 22$ matrix, $\mathbf{b}$ an unknown 22 -elements vector. The first 18 elements of $\mathbf{b}$ are the reference velocities at 18 station pairs and the remaining 4 elements of $\mathbf{b}$ are average upwelling velocities between each of the adjacent layers. A detailed description of Method 2 is given by Yuan et al. [1992].

\section{Results and Comparisons}

[7] The inverse calculation output is the velocity vector $\mathbf{b}$. Absolute geostrophic velocity profiles are obtained by adding the station-pair reference velocities contained in $\mathbf{b}$ to the hydrographically determined geostrophic velocity shears. Wrong values in $\mathbf{b}$ will contaminate the absolute velocity profile not only at the reference level but through the entire water column. The best way to determine whether or not an obtained solution is realistic is to check velocity in the lower layers. This is because erroneous velocities are often masked by strong, complex structures in the upper layer. We will therefore focus on deep velocity structures at 1000- to 3000-dbar levels, which N2007 did not show.

[8] Remarkably, the results from our two inverse-method calculations using a 2000-dbar reference level show no strong currents in these deep layers while the results from using a 100-dbar reference level (as in N2007) do (Figures 2-4). In our results, velocities deeper than 1500 dbar are less than $10 \mathrm{~cm} \mathrm{~s}^{-1}$ on all three lines, while the largest-magnitude current velocities from the N2007 inverse calculation are -57 and $46 \mathrm{~cm} \mathrm{~s}^{-1}$ at $3100 \mathrm{dbar}$ and 2315 dbar on the AE and OS lines, respectively. The northeastward RCS velocities from our inversions are stronger than those from N2007 in the AE and OS sections at the RCS core layer near 100-800 dbars. The areas of northeastward current from our results are larger than those from N2007. The maximum northeastward core velocities in the $\mathrm{AE}$ and OS sections from our results are $65 / 63$ and $36 / 36 \mathrm{~cm} \mathrm{~s}^{-1}$ (Method 1/Method 2), while those from N2007 are 56 and $30 \mathrm{~cm} \mathrm{~s}^{-1}$. 


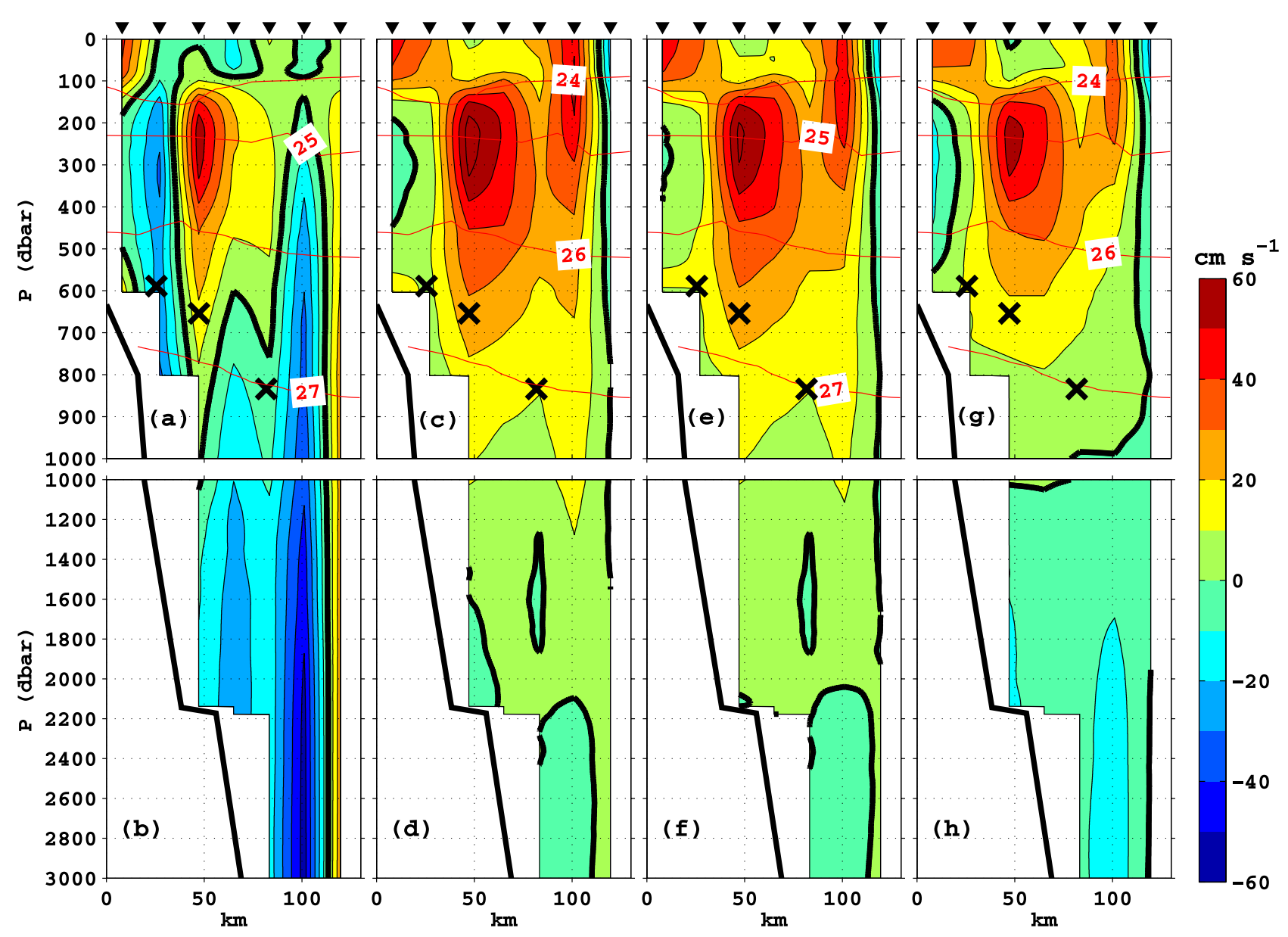

Figure 2. Absolute geostrophic velocity at the $\mathrm{AE}$ line. Black contours filled with color indicate current velocity with $10 \mathrm{~cm} \mathrm{~s}^{-1}$ interval. Positive value indicates northeastward velocity. Red contours indicate potential density with $1 \sigma_{\theta}$ interval. Shown are (a) 0-1000 dbars and (b) 1000-3000 dbars from N2007 inverse calculation results; (c) 0-1000 dbars and (d) 1000-3000 dbars calculated by Method 1; (e) $0-$ $1000 \mathrm{dbars}$ and (f) 1000-3000 dbars calculated by Method 2; and (g) 0-1000 dbars and (h) 1000-3000 dbars calculated by Method 1 using 1000-dbar reference level. Thick contours show 0 velocity. Inverted triangles indicate the locations of inverse computational points. Crosses indicate the positions of current meters PK1-4, PK2-4, and PK3-4 along the AE line. 


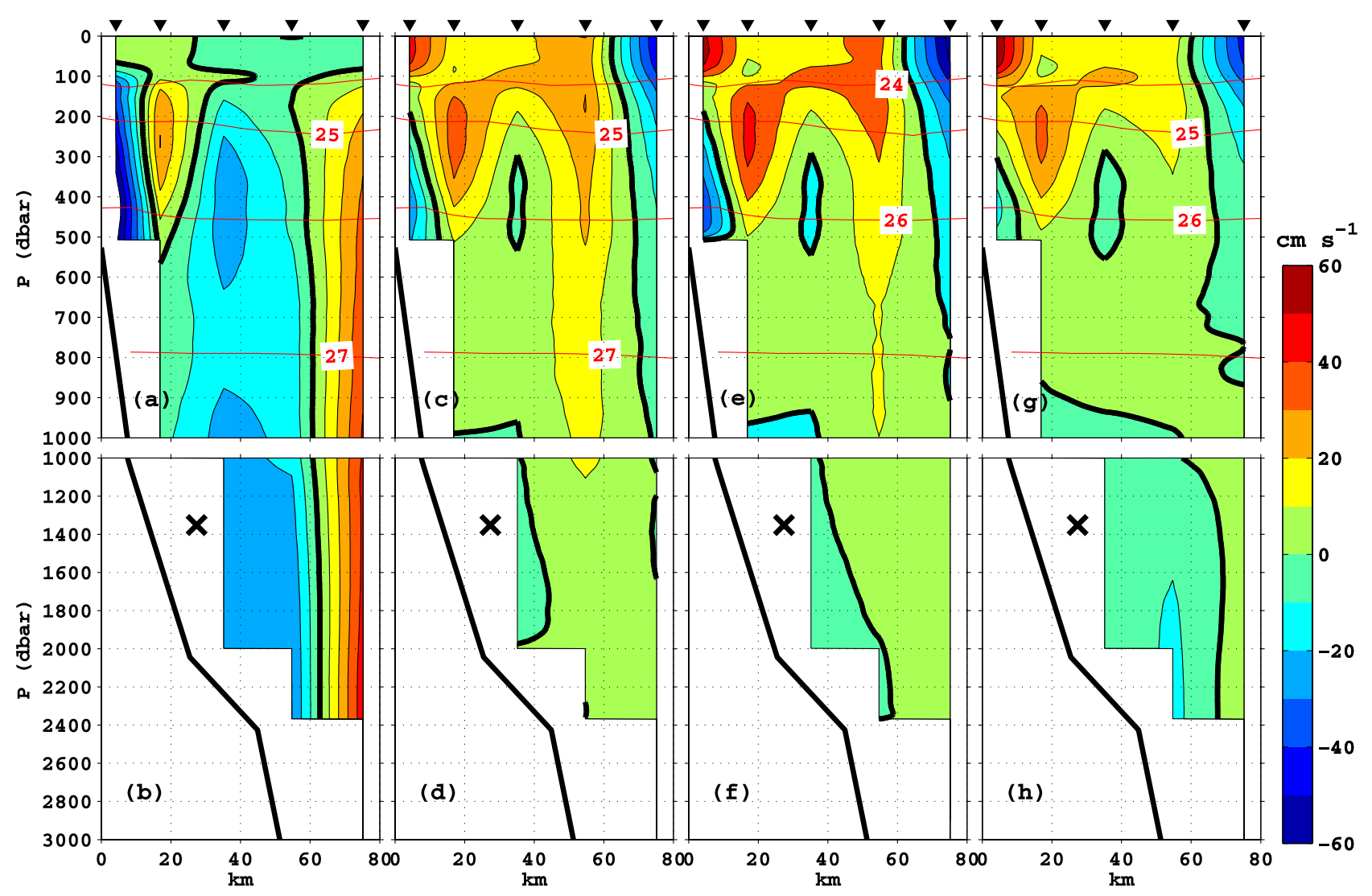

Figure 3. Same as Figure 2 except for the OS line. Cross indicates approximate position of current meter ACM031. 


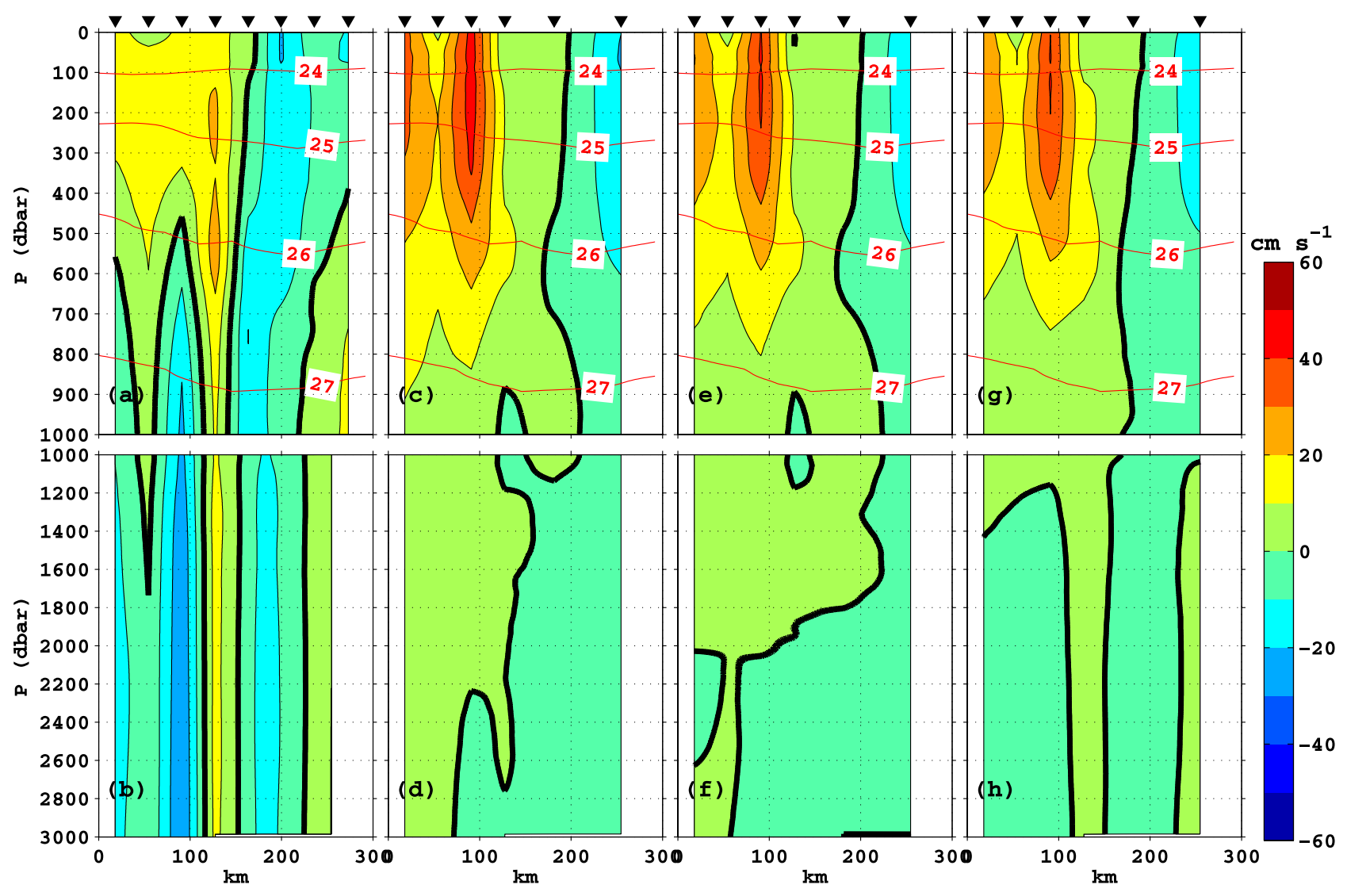

Figure 4. Same as Figure 2 except for the E line. Positive value indicates northwestward velocity.

[9] The volume transports estimated by our inverse methods are quite different from those of N2007. For example, net transport and northeastward transport across the AE line in the upper 1000-dbar layer are respectively 22.4/21.5 and 20.9/20.1 Sv from Method 1/Method 2 calculations, but only 2.2 and $11.4 \mathrm{~Sv}$ from N2007. The full-water-column countercurrent transports across the AE and OS lines are $-1.9 /-1.9$ and $-5.2 /-3.6 \mathrm{~Sv}$ from Method 1/Method 2 calculations, but -39.4 and $-19.7 \mathrm{~Sv}$ from N2007. Note that the N2007 full-water-column inflow and outflow transports across the $\mathrm{E}$ line reach the large values of 46.1 and $-81.3 \mathrm{~Sv}$. Table 1 gives detailed comparisons between our inverse results and those of N2007, of volume transports above and below 1000 dbar across each line. Table 2 similarly compares volume transports in layers separated by isopycnals.

[10] Ichikawa et al. [2004] report direct current measurements from an AE line current-meter array that was in operation during the October hydrographic cruise (see locations of PK1-4, 2-4 and 3-4 in Figure 1). Additionally, in situ currents were measured near the OS line (see location of ACM031 in Figure 1). The ACM031 data were provided by the Kuroshio Transport and Surface Flux Group/ JAMSTEC, from their web site http://www.jamstec.go.jp/ iorgc/ocorp/ktsfg/data/index.html.

[11] Except for a few brief periods, measured currents at the AE line show positive flow toward the northeast (Figure 6). During the October cruise, all of the current meter measurements at PK1-4 (589 m), PK2-4 (654 m) and PK3-4 (834 m) show northeastward currents (see arrow on the $\mathrm{x}$ axis in Figure 6). The currents estimated by our inverse calculations at the three current meter moorings are all positive, and hence their directions are consistent with those observed by the current meter moorings. However, the currents estimated by N2007 at PK1-4 and PK3-4 are negative, and hence their directions are opposite from those observed by the current meter moorings.

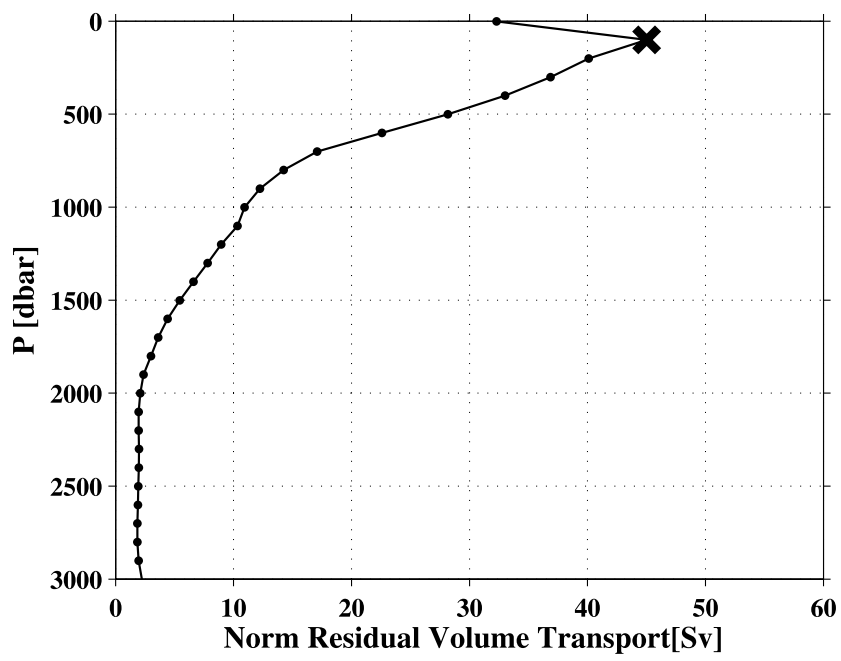

Figure 5. Norm residual volume transport (in Sverdrups) as a function of different reference levels with a 100-dbar interval. Cross shows the 100-dbar reference level used by N2007. 
Table 1. Comparison of Upper 1000dbar/Full-Water-Column Volume Transports Across the AE, OS, and E Lines ${ }^{\mathrm{a}}$

\begin{tabular}{ccccc}
\hline \hline Section & Method & Net (Sv) & NE (Sv) & SW (Sv) \\
\hline \multirow{2}{*}{ AE } & N2007 & $2.2 /-14.1$ & $11.4 / 25.3$ & $-9.2 /-39.4$ \\
& Method 1 & $20.9 / 23.2$ & $22.4 / 25.3$ & $-1.4 /-1.9$ \\
& Method 2 & $20.1 / 22.0$ & $21.5 / 23.9$ & $-1.4 /-1.9$ \\
OS & N2007 & $0.1 / 13.7$ & $7.6 / 33.3$ & $-7.5 /-19.7$ \\
& Method 1 & $4.4 / 4.3$ & $7.9 / 9.5$ & $-3.5 /-5.2$ \\
& Method 2 & $4.2 / 4.7$ & $6.8 / 8.3$ & $-2.6 /-3.6$ \\
\hline Section & Method & Net(Sv) & NW (Sv) & SE (Sv) \\
\hline \multirow{2}{*}{ E } & N2007 & $2.2 /-35.2$ & $16.6 / 46.1$ & $-14.4 /-81.3$ \\
& Method 1 & $16.9 / 19.1$ & $26.7 / 34.0$ & $-9.8 /-14.8$ \\
& Method 2 & $15.8 / 17.2$ & $23.8 / 27.4$ & $-8.0 /-10.2$ \\
\hline \hline
\end{tabular}

${ }^{\mathrm{a}}$ Top part of the table gives net, northeastward (NE), and southwestward (SW) volume transports across the $\mathrm{AE}$ and $\mathrm{OS}$ lines. Positive value indicates northeastward volume transport. Bottom part of table gives net, northwestward (NW), and southeastward (SE) volume transports across the $\mathrm{E}$ line. Positive value indicates northwestward volume transport.

[12] Current velocity normal to the OS line observed at ACM031 shows a week deep current at $1352 \mathrm{~m}$ depth (Figure 7). During the October cruise, the observed current velocity is $-3.9 \mathrm{~cm} \mathrm{~s}^{-1}$, close to our inverse calculation results of $-1.8 /-2.3 \mathrm{~cm} \mathrm{~s}^{-1}$ (Method 1/Method 2), but quite different from the $\mathrm{N} 2007$ result of $-25.6 \mathrm{~cm} \mathrm{~s}^{-1}$. Note that the horizontal distance between ACM031 and the velocity computational point is about $14.7 \mathrm{~km}$. Comparisons of velocities from our inverse calculations and from N2007 with in situ current meter measurements are summarized in Table 3.

\section{Discussion}

[13] In the region southeast of Amami-Ohshima, 4 years of current-meter measurements along the AE line at nominal depths of 454-2317 $\mathrm{m}$ showed current flowing almost always northeastward, and in particular doing so during the three cruises, except at PK1 in May-June. Moreover there is no strong southwestward current at 1500-3000 dbars in the yearly mean velocity sections [Ichikawa et al., 2004, Figure 7]. Using inverse methods (2000-dbar reference), absolute geostrophic velocity deeper than $2000 \mathrm{dbar}$ was estimated to be less than $5 \mathrm{~cm} \mathrm{~s}^{-1}$ in the fall of 2000 [Zhu et al., 2005, Figure 2] and had a maximum of about $10 \mathrm{~cm} \mathrm{~s}^{-1}$ in September 1987 [Nakano et al., 1994, Figure 9]. In the region southeast of Okinawa, absolute velocity sections from inverse calculations (reference levels from 1500 to 2500 dbar) also showed values smaller than $5 \mathrm{~cm} \mathrm{~s}^{-1}$ in the layer deeper than 2000 dbar [Yuan et al., 1994, 1995, 1998; Liu and Yuan, 2000; Zhu et al., 2005].

[14] Figure 5 shows 100 dbar to be the worst reference level, because it has the largest initial water mass imbalance. We performed inverse calculations using a 100-dbar reference level, and obtained a solution with strong deep flows that disagree with current-meter measurements. Large errors in the N2007 results are apparently caused by the shallow reference level of $100 \mathrm{dbar}$.

[15] In N2007, the mass imbalance from the inverse calculation is $\mathrm{O}\left(10^{-5} \mathrm{~Sv}\right)$, almost zero (see Table 2 in N2007). But for a general ocean inverse problem such as equation (1), the mass is not accurately balanced in a real ocean model. The errors due to observations will influence the inverse solution $\mathbf{b}$ in equation (1). A large magnitude of initial mass imbalance $(\Gamma)$ can generate a large error deviation b in Method 1 (see equation (31) of Wunsch [1978] for details), which can make the strong deep currents extend to the bottom through the dynamic calculation. In their concluding remarks, Fiadeiro and Veronis [1982] state: "An inverse solution that eliminates all residuals will require large barotropic corrections and noise will dominate the final solution, rendering it meaningless. Even an approximate solution that starts off with a bad initial reference level will require large corrections with a concomitant amplification of noise. That is one reason why earlier inverse analyses led to equivocal results. It is necessary to make the correction near the best possible assumed reference surface to insure that the required correction is small. Our analytical search procedure, based on the minimum possible $\mathbf{b}^{2}$, helps to locate the vicinity of the optimum surface and the trade-off completes the task. It is important also to make the minimal correction required to force the imbalance to lie within acceptable (noise) limits and thereby avoid the sensitivity to noise". This prophetically describes the poor choices made in N2007's inverse calculations, and also explains how N2007 presented such strong deep currents in the RCS from their inverse results.

[16] N2007 discuss the reliability of their inverse calculation by comparing the results with the R/V Chofu-maru shipboard ADCP-referenced geostrophic velocity. But those ADCP data are unsuitable for two reasons: (1) since only the processed data were recorded, it was not possible to postprocess the raw ADCP measurements in order to remove bad data resulting from variations of ship's heading in the deep-water region where bottom-track mode could not be used [Zhu and Ichikawa, 2003], and (2) ageostrophic velocity components due to tides, inertial motions, etc., are included in the ADCP measurements.

[17] N2007 say they selected $100 \mathrm{dbar}$ as a reference level because the level must not be in the velocity core of the RCS (see paragraph 14 in N2007); their inverse results show the 100-dbar level is at the upper boundary of this core (Figures 2c and 3c in N2007). But they could have chosen a level below the core instead. During the other two cruises (May-June and September), XBT/XCTD casts to a maximum depth of about $1000 \mathrm{~m}$, were taken along the $\mathrm{E}$ line. We therefore tested our inverse calculations for the October cruise data using a 1000-dbar reference level (Figures 2g, 2h, 3g, 3h, 4g and 4h). Allowing a mass imbalance of up to $1 \mathrm{~Sv}$ for each layer, the velocity structures in the top 1000-dbar layer were similar to those estimated using a 2000-dbar reference level, while the

Table 2. Comparison of Volume Transports Across the AE, OS, and E Lines for Upper and Lower Potential-Density Layers ${ }^{\mathrm{a}}$

\begin{tabular}{lcccc}
\hline Layer & Method & AE (Sv) & OS (Sv) & E (Sv) \\
\hline $24-26 \sigma_{\theta}$ & N2007 & $6.0(3.1)$ & $3.1(0.2)$ & $8.2(2.8)$ \\
& Method 1 & $11.0(10.2)$ & $4.0(2.4)$ & $14.1(7.8)$ \\
& Method 2 & $10.6(9.9)$ & $3.3(2.0)$ & $13.3(8.4)$ \\
$26-28 \sigma_{\theta}$ & N2007 & $4.2(-1.4)$ & $4.2(0.0)$ & $6.3(-1.4)$ \\
& Method 1 & $9.8(9.8)$ & $3.2(1.5)$ & $14.3(8.2)$ \\
& Method 2 & $9.6(8.9)$ & $3.5(2.3)$ & $10.8(6.7)$ \\
\hline
\end{tabular}

${ }^{\mathrm{a}}$ Volume transport positive toward northeast across the AE and OS lines, positive toward the northwest across the $\mathrm{E}$ line. Numbers in parentheses are net volume transports across each line. 


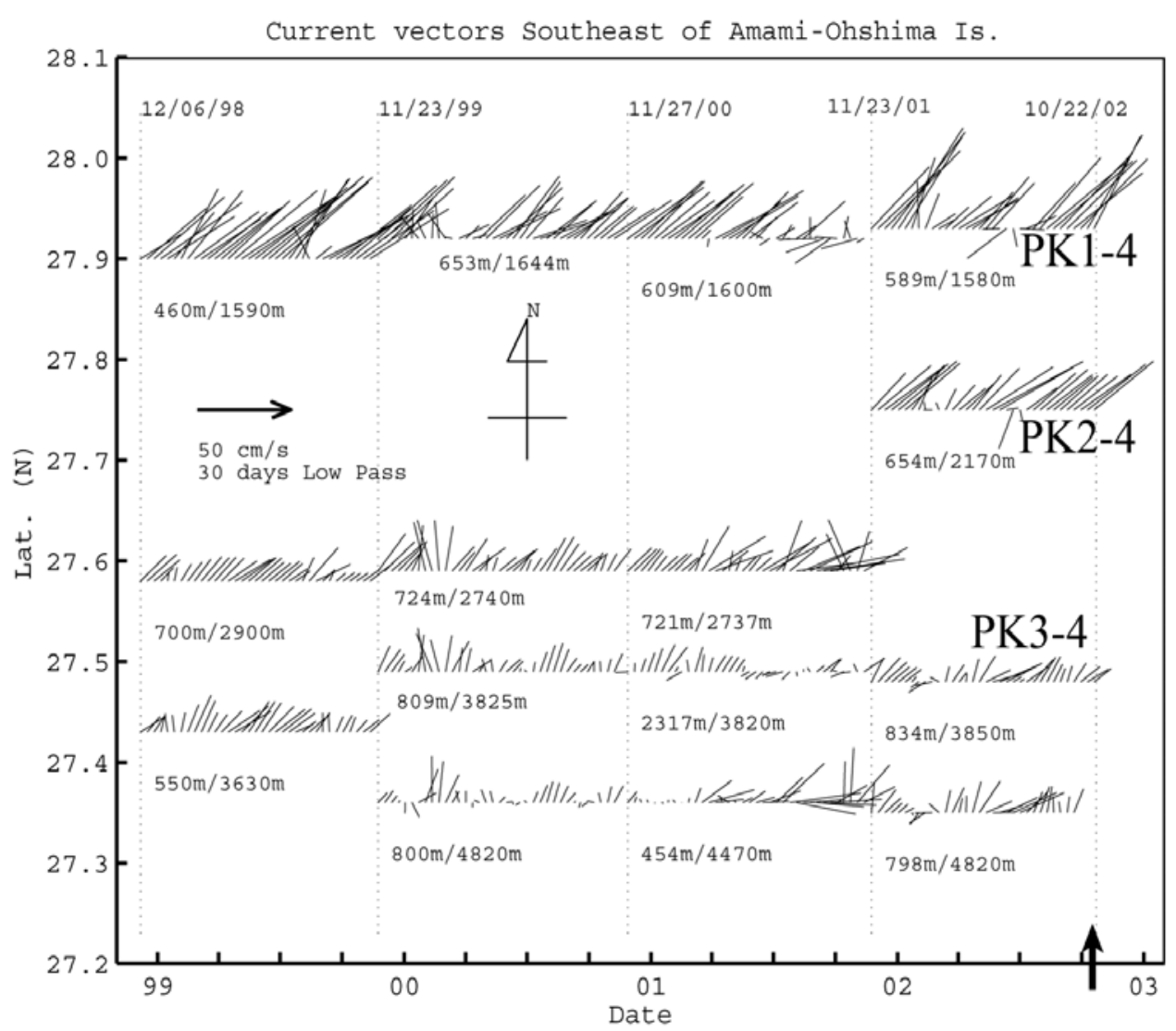

Figure 6. Stick diagrams of currents observed southeast of Amami-Ohshima (locations are shown in Figure 1). Upward points north. The velocities are displayed every 10 days after smoothing by a low-pass filter with 30-day-period half power gain. Ticks labeled by years on the $\mathrm{x}$ axis indicate 1 January of each year [after Ichikawa et al., 2004]. Arrow on the $\mathrm{x}$ axis approximately indicates the time of the October cruise.

northeastward velocities and volume transport of the RCS became smaller, and southwestward countercurrents larger than $10 \mathrm{~cm} \mathrm{~s}^{-1}$ appeared at depths beyond $1500 \mathrm{dbar}$ in the $\mathrm{AE}$ and $\mathrm{OS}$ sections. Nevertheless, the inverse results with a 1000-dbar reference level showed RCS structures that are much improved over those using a 100-dbar reference level.

[18] In the present inverse method, we considered the conservation of salt and allowed a small mass imbalance while N2007 did not. Of course, an inverse calculation with different assumptions can obtain different results, although the same reference level is used. We tested our inverse calculations using a 2000-dbar reference level, without the conservation of salt and almost no mass imbalance for Method 1. The result shows no strong deep currents: rootmean-square change of the solution for deep-water station pairs is $2.5 \mathrm{~cm} \mathrm{~s}^{-1}$. Therefore, the main reason for the unrealistic strong deep currents in N2007 is the poor choice of reference level. In fact, the assumptions used in the

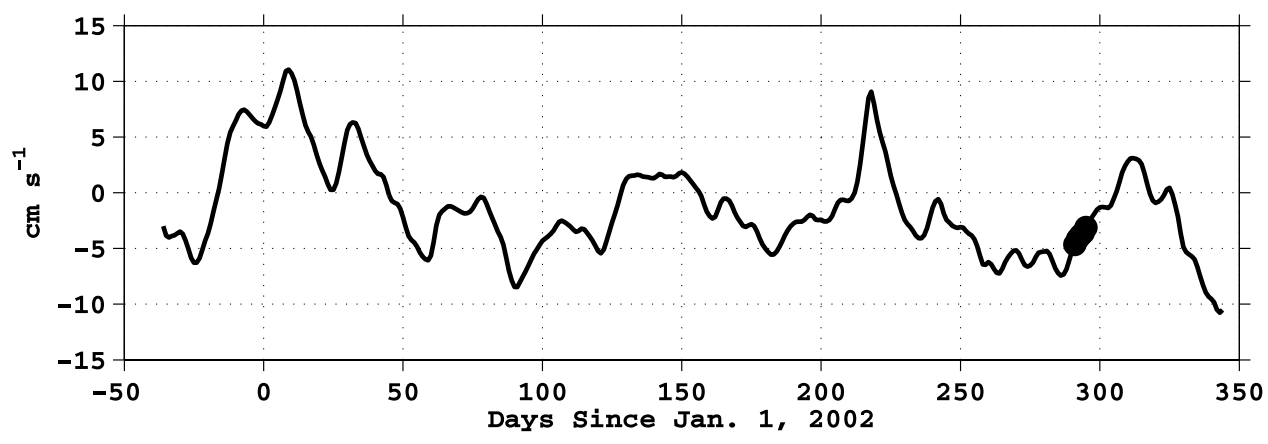

Figure 7. Normal-to-OS-line component of 1352-m-depth current velocity (positive toward northeast) observed by current meter at ACM031 southeast of Okinawa (location is shown in Figure 1). Tides have been removed and the data are smoothed by a 10-day low-pass filter. Black dots indicate time of the October cruise during days 291-295 (18-22 October 2002). 
Table 3. Comparison of Velocities From Inverse Calculations With Current Meter Measurements ${ }^{\mathrm{a}}$

\begin{tabular}{cccccc}
\hline CM Station Name & CM/Water Depth $(\mathrm{m})$ & N2007 $\left(\mathrm{cm} \mathrm{s}^{-1}\right)$ & Method 1 $\left(\mathrm{cm} \mathrm{s}^{-1}\right)$ & Method 2 $\left(\mathrm{cm} \mathrm{s}^{-1}\right)$ & CM $($ Direction or cm s \\
\hline PK1-4
\end{tabular}

${ }^{a}$ Positive value indicates northeastward current velocity. "NE" indicates northeastward current direction.

present inverse method, are appropriate for the real ocean, and improve the accuracy of the inverse solution.

[19] It is well known that mesoscale eddies influence the RCS both in velocity structure and volume transport [Zhu et al., 2003]. A map of absolute sea level (ASL) shows an anticyclonic eddy covered the $\mathrm{E}$ line and southern end of the AE line during the October cruise (Figure 5c in N2007). In agreement with the ASL distribution, our upper-watercolumn velocity sections exhibit respectively the northwestward and southeastward currents at the southern and northern ends of the $\mathrm{E}$ line (Figures $4 \mathrm{c}, 4 \mathrm{e}$ and $4 \mathrm{~g}$ ), and northeastward and southwestward currents on the shoreward and seaward sides of the zero-velocity contour near $\mathrm{x}=110 \mathrm{~km}$ on the AE line (Figures 2c, 2e and 2g). However, in this part of the N2007 AE velocity section a reverse pattern is seen (Figure 2a), which differs with the ASL distribution and which extends to the bottom. It should be noted that mesoscale eddies observed in this region are limited to the upper $1000 \mathrm{~m}$ [Zhu et al., 2002; Takikawa et $a l ., 2005]$, which is what our velocity sections show.

\section{Conclusion}

[20] In this note, we used two inverse methods to calculate the current east of the Ryukyu Islands from hydrographic section data collected in October 2002. We compared our inverse calculation results with those of $\mathrm{N} 2007$, and found that they are significantly different in both velocity structures and volume transports. The differences were especially notable in the deep layer, where results from N2007 showed strong currents with velocities up to $50 \mathrm{~cm} \mathrm{~s}^{-1}$. Comparisons of inverse calculation results with in situ current-meter measurements and previous observations indicate that our inverse calculation results present more realistic velocity structures and volume transports of the RCS than those of N2007. We confirmed that the unrealistic strong deep currents from the N2007 inverse calculation result from a poor choice of reference level. Through this example we would like to call attention to the importance of appropriate choices when an inverse method is used to calculate absolute geostrophic velocity.

[21] Acknowledgments. The hydrographic survey was conducted onboard the R/V Chofu-maru of Nagasaki Marine Observatory, Japan Meteorological Agency. The first author, who was the chief scientist on the JAMSTEC side, acknowledges Captain Eguchi and his crew for their support in the shipboard operations. We thank A. Nagano for providing us the inverse results of $\mathrm{N} 2007$ that improved this paper through more detailed comparisons. We also thank H. Ichikawa, who made the ACM031 currentmeter data available on the JAMSTEC web site. We acknowledge Isao Koike, President of the Oceanographic Society of Japan (JOS), for his permission to use Figure 6, whose copyright belongs to JOS. X.-H. Zhu was supported by the National Natural Science Foundation of China under grant 40776021, the National Basic Research Program of China under grant 2006CB400603, and the National High Technology Research and Development Program of China under grant 2006AA09Z102. The work of J.-H.
Park and M. Wimbush was supported by the Office of Naval Research under grant N000140210271. Two anonymous reviewers are acknowledged for their critical comments and valuable suggestions on the manuscript.

\section{References}

Fiadeiro, M. E., and G. Veronis (1982), On the determination of absolute velocity in the ocean, J. Mar. Res., 40, suppl., 159-182.

Ichikawa, H., H. Nakamura, A. Nishina, and M. Higashi (2004), Variability of northeastward current southeast of northern Ryukyu Islands, J. Oceanogr., 60, 351-363.

Kaneko, I., Y. Takatsuki, and H. Kamiya (2001), Circulation of intermediate and deep waters in the Philippine Sea, J. Oceanogr., 57, 397-420.

Liu, Y. G., and Y. C. Yuan (2000), Variation of the currents east of Ryukyu Islands in 1998, Mer, 38, 179-184.

Nagano, A., H. Ichikawa, T. Miura, K. Ichikawa, K. Konda, Y. Yoshikawa, K. Obama, and K. Murakami (2007), Current system east of the Ryukyu Islands, J. Geophys. Res., 112, C06009, doi:10.1029/2006JC003917.

Nakano, T., I. Kaneko, and Y. Takatsuki (1994), The Kuroshio structure and transport estimated by the inverse method, J. Phys. Oceanogr., 24, 609618.

Takikawa, T., H. Ichikawa, K. Ichikawa, and S. Kawae (2005), Extraordinary subsurface mesoscale eddy detected in the southeast of Okinawa in February 2002, Geophys. Res. Lett., 32, L17602, doi:10.1029/ 2005 GL023842.

Wunsch, C. (1978), The North Atlantic general circulation west of $50^{\circ} \mathrm{W}$ determined by inverse methods, Rev. Geophys., 16, 583-620.

Yuan, Y., J. Su, and Z. Pan (1992), Volume and heat transports of the Kuroshio in the East China Sea in 1989, Mer, 30, 251-262.

Yuan, Y. C., K. Takano, Z. Pan, J. Su, K. Kawatate, S. Imawaki, H. Yu, H. Chen, H. Ichikawa, and S. Umatani (1994), The Kuroshio in the East China Sea and the currents east of the Ryukyu Islands during autumn 1991, Mer, 32, 235-244.

Yuan, Y. C., J. Su, Z. Pan, H. Chen, H. Ichikawa, S. Imawaki, K. Kawatate, K. Takano, and S. Umatani (1995), The western boundary current east of the Ryukyu Islands, Mer, 33, 1-11.

Yuan, Y. C., A. Kaneko, J. Su, X.-H. Zhu, Y. Liu, N. Gohda, and H. Chen (1998), The Kuroshio east of Taiwan and in the East China Sea and the currents east of Ryukyu Islands during early summer of 1996, J. Oceanogr., 54, 217-226.

Zhu, X.-H., and H. Ichikawa (2003), Chofu-Maru data report for KOP02-03 cruise (in Japanese), pp. 1-20, Jpn. Agency for Mar.-Earth Sci. and Technol., Yokosuka, Japan.

Zhu, X.-H., I.-S. Han, J.-H. Park, H. Ichikawa, A. Kaneko, A. Ostrovskii, N. Gohda, and S. Umatani (2002), Observation of current and eddy activity east of Okinawa Island, paper presented at 6th Pacific Ocean Remote Sensing Conference, Min. of Mar. Affairs and Fish., Natl. Inst. of Aeron. and Space, Res. and Dev. Cent. for Oceanol., Bali.

Zhu, X.-H., I.-S. Han, J.-H. Park, H. Ichikawa, K. Murakami, A. Kaneko, and A. Ostrovskii (2003), The northeastward current southeast of Okinawa Island observed during November 2000 to August 2001, Geophys. Res. Lett., 30(2), 1071, doi:10.1029/2002GL015867.

Zhu, X.-H., J.-H. Park, and I. Kaneko (2005), The northeastward current southeast of Ryukyu Islands in early winter of 2000 estimated by an inverse technique, Geophys. Res. Lett., 32, L05608, doi:10.1029/ 2004GL022135.

Zhu, X.-H., J.-H. Park, and I. Kaneko (2006), Velocity structures and transports of the Kuroshio and the Ryukyu Current during fall of 2000 estimated by an inverse technique, J. Oceanogr., 62, 587-596.

J.-H. Park and M. Wimbush, Graduate School of Oceanography, University of Rhode Island, 215 South Ferry Road, Narragansett, RI 02882-1197, USA.

C.-H. Yang and X.-H. Zhu, Second Institute of Oceanography, State Oceanic Administration, State Key Laboratory of Satellite Ocean Environment Dynamics, 36 Bao-chu-bei Road, Hangzhou, Zhejiang 310012, China. (xhzhu001@yahoo.com.cn) 